\title{
Operando Flow Regime Diagnosis using Acoustic Emission in a Polymer Electrolyte Membrane Water Electrolyser
}

M. Maiera, Q. Meyer ${ }^{b}$, J. Majasana, C. Tana, I. Dedigama ${ }^{a}$, J. Robinson ${ }^{a}$, J. Dodwella, Y. Wua, L. Castanheirac, G. Hinds' $^{c}$, P.R. Shearing ${ }^{a}$, D.J.L. Bretta ${ }^{*}$

${ }^{a}$ Electrochemical Innovation Lab, Department of Chemical Engineering, UCL, London, WC1E 7JE, United Kingdom

${ }^{b}$ Nanoelectrochemistry Group, School of Chemistry, UNSW, Sydney, 2052, Australia

${ }^{c}$ National Physical Laboratory, Hampton Road, Teddington, Middlesex, TW11 OLW, UK

"Corresponding author. Tel.: +44 (0)20 7679 3310; fax: +44 (0)20 7383 2348. E-mail

address: d.brett@ucl.ac.uk (D.J.L. Brett).

\section{Abstract}

Polymer electrolyte membrane water electrolysers (PEMWE) are a key technology for producing clean ('green') hydrogen for decarbonisation of the transport sector and grid stabilization utilising increasing levels of renewable energy. Understanding the complex interplay of factors that affect device operation is key to improving the technology and advanced diagnostic techniques have a major role to play. In this work, acoustic emission analysis is used as a non-destructive, operando diagnostic tool to provide information about the relative number and size of gas bubbles generated locally within a PEMWE, providing effective characterization of the local flow regime. An optically transparent single-channel PEMWE is used to investigate the relationship between the acoustic signals obtained and the two-phase flow conditions inside the cell. Results show good correlation between the number of acoustic 'hits' and the number of bubbles passing through the flow channel. The size of bubbles is also shown to affect the average frequency of the hits. Consequently, the transition between flow regimes can be identified by acoustic emission analysis, paving the way for a simple, low-cost, nondestructive means of mapping flow inside commercial-scale PEMWEs.

Keywords: Acoustic Emission; PEM Water Electrolyser; Operando Diagnostics; Flow Regime; High-Speed Imaging 


\section{Introduction}

Industrial scale, carbon-free hydrogen production is increasingly seen as a key enabling technology for the decarbonisation of road transport through the use of fuel cells and stabilisation of electricity grids containing increasing amounts of renewable energy generators. Steam reforming of methane is currently the predominant means of hydrogen production due to its lower cost and higher capacity. However, evolving emissions regulations, the falling cost of water electrolysers, and increasing access to renewable sources of electricity are set to make this electrochemical route to hydrogen production the preferred long-term solution [1,2]. Polymer electrolyte membrane water electrolysers (PEMWE) have only recently reached industrial maturity, with recent plants rated up to $6 \mathrm{MW}$ [3]. Capital cost of PEMWE plants has not yet reached that of alkaline electrolysis [4], but PEMWE have some inherent advantages over alkaline electrolysis, including higher current densities, low gas crossover and a compact design [2]. However, there remains a need to reduce the cost and improve the performance and lifetime of the technology, which will require the development and optimization of novel diagnostic techniques.

The performance of a PEMWE is affected by various parameters including the temperature and pressure of operation, dynamic demand characteristics, water distribution, two-phase flow, etc. Understanding how these factors influence performance and durability is key to optimising electrolyser design, component materials and operating conditions. Various diagnostic techniques have been applied to PEMWEs to gain greater insight into their operation. These techniques range from low-cost, readily-available techniques such as electrochemical impedance spectroscopy to identify electrochemical losses in a system $[5,6]$ to high-end experiments such as neutron imaging used to visualize water content in the liquid-gas diffusion layer $[7,8]$, bubble dynamics and flow regimes [9-11].

This work aims to deliver a simple low-cost diagnostic of two-phase flow in operational PEMWEs without the need for any cell modification. 
It is well-known that the two-phase flow regime that exists within PEMWEs affects the electrochemical performance. Ito et al. $[12,13]$ have speculated that the coverage of extensive areas of the cell in slug flow leads to local water starvation and therefore reduces performance, while Dedigama et al. [6] concluded that performance is improved in slug flow, due to the increased rate of bubble removal from the surface of the liquid-gas diffusion layer. Furthermore, the flow regime affects the pressure drop of a system and therefore the energy necessary for water supply $[14,15]$. Hence, operando diagnosis of the flow regime within a PEM electrolyser enables performance optimisation and design improvement.

Acoustic emission (AE) testing is a non-destructive, in situ technique that detects transient elastic sound waves produced by a sudden redistribution of stress in a material or mechanical process. It has been extensively applied in building and structural health monitoring $[16,17]$ and uses a piezoelectric sensor to convert mechanical perturbations occurring in a system into a voltage signal. This allows the monitoring of sound waves emitted by an object. Whenever the signal exceeds a certain 'noise' threshold, an acoustic 'hit' is detected with its waveform being captured as a voltage-time profile. By analysing frequency, amplitude and number of hits as a function of time, it is possible to gain information on the process being monitored.

AE has been used to study electrochemical processes such as the exfoliation of aluminium alloys [18] or detection of corrosion in stainless steel [19]. It is increasingly being applied to power systems. For example, Ohzuku et al. [20] monitored particle fracture in $\mathrm{Li} / \mathrm{MnO}_{2}$ battery cells and found that accelerated discharge leads to increasing fracture. Rhodes et al. [21] monitored particle fracture in Sibased anodes of Li-ion batteries and showed that the fracture of Si particles can be modelled using a thermal analogy model [22]. This technique has also been applied to Li/NiSb 2 batteries [23], solid electrolyte interface (SEI) formation and Li intercalation in Li-ion batteries [24], solid oxide fuel cell seal cracking [25,26], Nafion dehydration [27], and flooding [28] and localised operation [29] in polymer electrolyte membrane fuel cells. 
There are several examples of using AE to diagnose two-phase systems. Pandit et al. [30] used a hydrophone immersed in an air-water system to calculate bubble size distribution. Yen et al. [31] extracted various criteria from the acoustic emission of an air-water system and trained a neural network to recognize different flow patterns. In other instances, AE has been applied to gas-solid beds [32], annular and stratified flow in gas-liquid pipelines [33] and measurement of the gas void fraction during slug flow [34]. Husin et al. [35] showed that the formation and collapse of single bubbles can be studied using acoustic emission and also reported a signal specific to the movement of slug bubbles. The only previous report of the application of AE to electrolysis comes from Crowther et al. [36], who studied the onset of gas evolution in alkaline electrolysis. However, to the best of our knowledge, there have been no publications concerned with the acoustic emission of PEMWE in general, or the flow regime in a PEMWE specifically. Based on the range of studies reported, it is hypothesized that the action of gas evolution, bubble formation and convective transport in a PEMWE can generate an acoustic signature measurable from the external surface of a cell, that could act as a diagnostic of the internal working (two-phase flow) of the system (Figure 1). To demonstrate this, correlation of $A E$ with a direct characterisation of two-phase flow is required. An unequivocal means of doing this is through direct flow visualisation.

Bubble formation and movement in PEMWEs have been captured using high-speed imaging. Dedigama et al. $[6,37]$ have imaged different flow regimes and established high-speed imaging as a diagnostic tool for PEMWEs. Lafmejani et al. $[38,39]$ used high-speed imaging to illustrate flow regimes in a vertical flow channel and linked these flow regimes to typical operating current densities. A number of studies have used high-speed imaging to investigate the formation of gas bubbles directly on the catalyst surface, using perforated titanium foils as a liquid-gas diffusion layer, allowing for optical access to the catalyst layer [5,40-42].

This work will combine high-speed flow visualisation using a single-channel optical PEMWE with local AE to correlate acoustic signals with flow characteristics with a view to establishing a diagnostic tool for standard (unmodified) PEMWEs. 

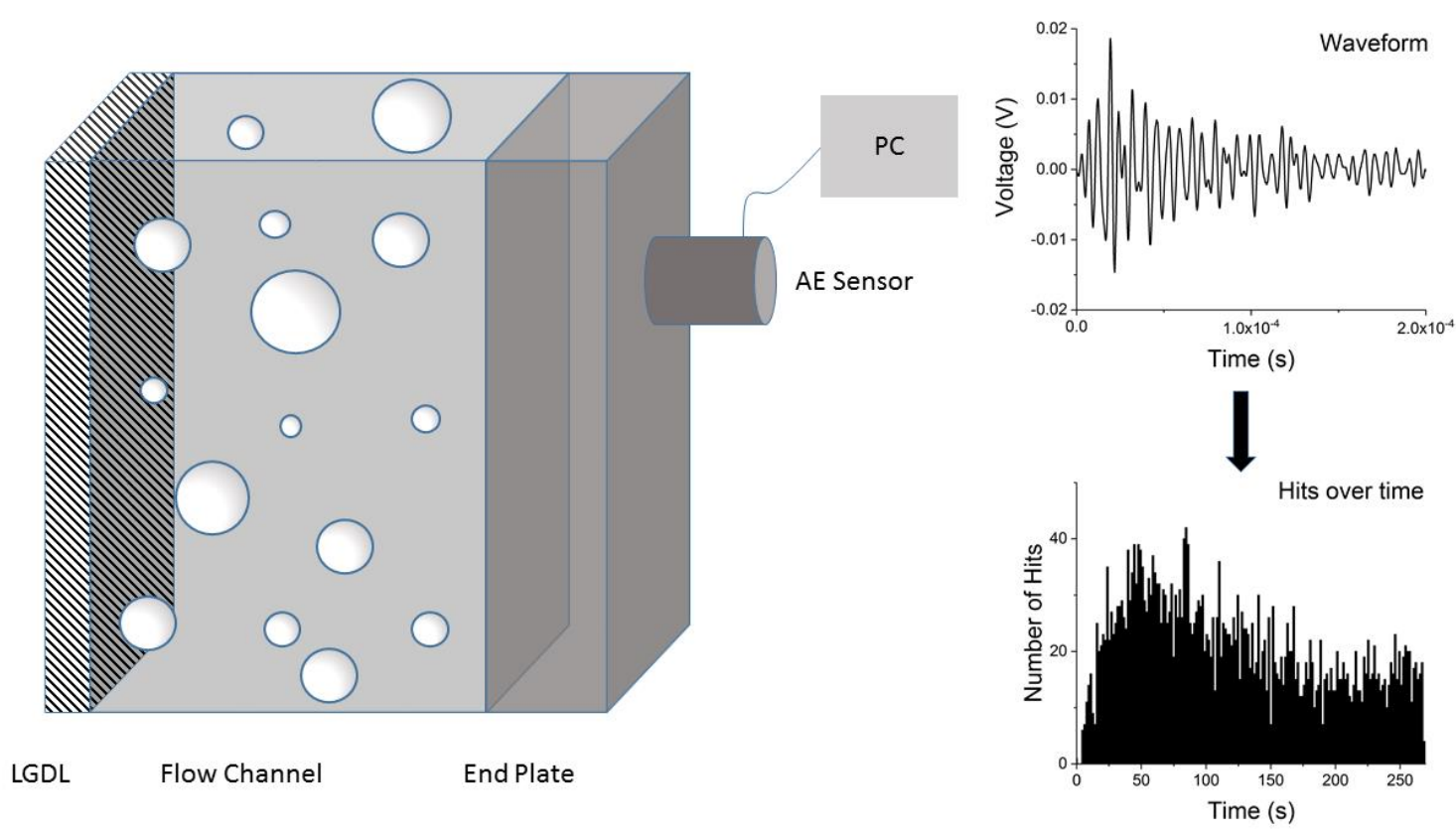

Fig. 1. Application of acoustic emission to the flow channel of a PEM water electrolyser. The raw signal (waveform) of one acoustic hit and an example of how the number of hits changes over time are shown on the right.

\section{Experimental}

\subsection{PEMWE Cell}

In order to correlate the acoustic emission signature with local flow characteristics, an optically transparent cell was constructed (Figure 2 (a)). This comprised a single flow channel, which mitigates the uneven distribution of flow in multi-channel systems (Nie et al. [43]) and ensures the influence of different flow rates and current densities can be examined. The electrochemical performance of the cell can be seen in Figure 2 (b). The single channel had a length of $9 \mathrm{~cm}$, a width of $5 \mathrm{~mm}$, a depth of 2 $\mathrm{mm}$, and an active area of $13.5 \mathrm{~cm}^{2}$. Transparent Perspex was used as the material for the end-plates, allowing for optical inspection and operando high-speed imaging of bubble development and movement. The cell was held together with twelve tie bolts with a torque of $1.5 \mathrm{Nm}$ applied to them to ensure good sealing and electrical contact. Sintered titanium powder was used as liquid-gas diffusion layer (LGDL) on both the anode and cathode side. A catalyst coated membrane (CCM) based on Nafion 115, with $0.6 \mathrm{mg} \mathrm{cm} \mathrm{cm}^{-2}$ platinum on the cathode and $3 \mathrm{mg} \mathrm{cm} \mathrm{cm}^{-2}$ 
(a)

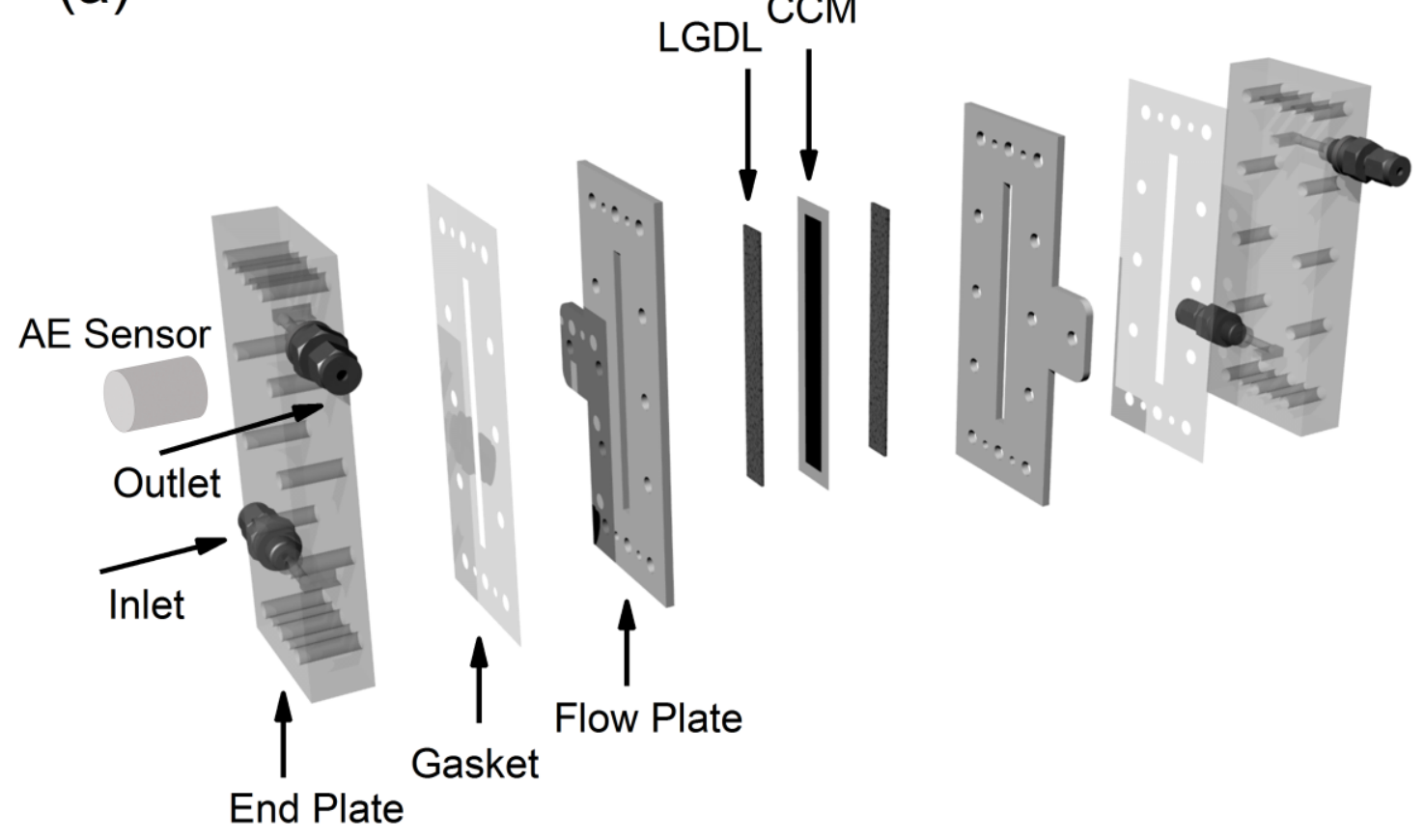

(b)

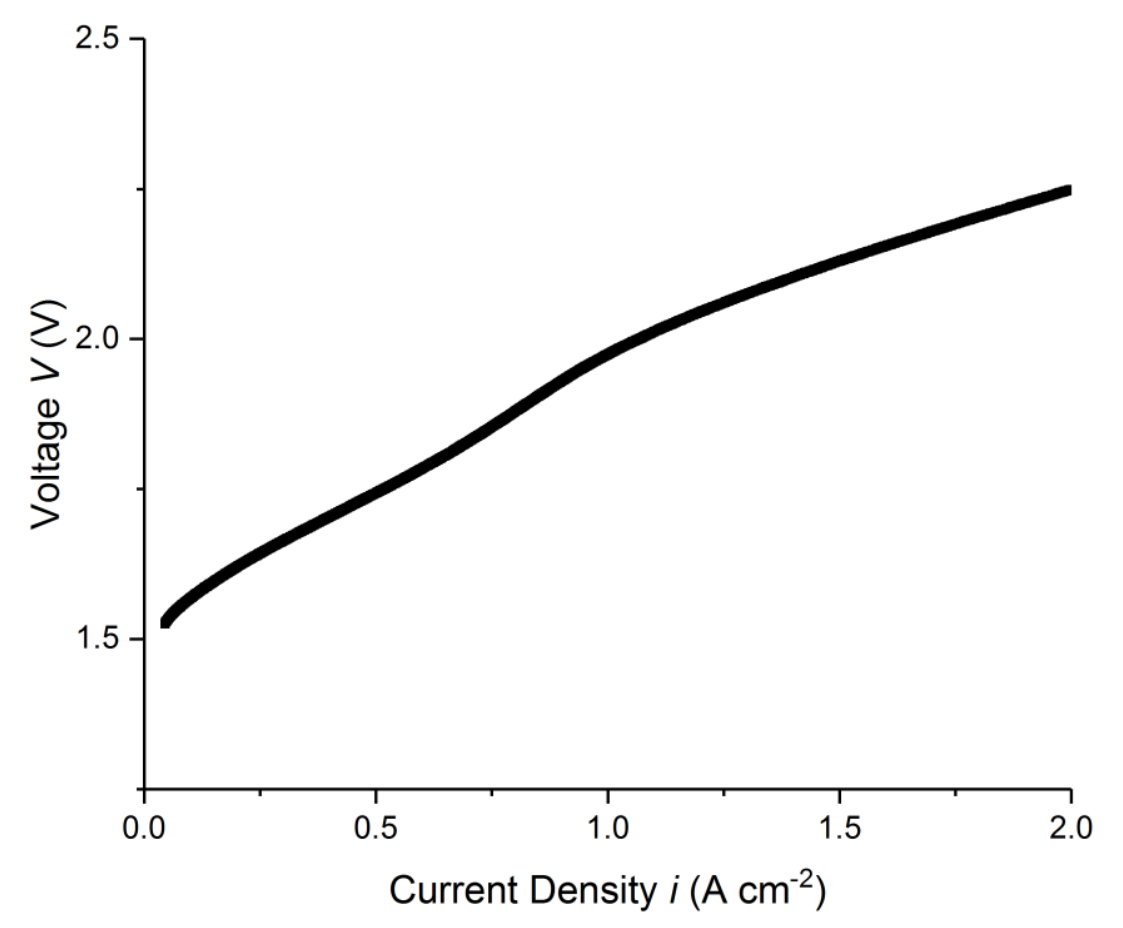

Fig. 2. (a) Assembly of the optically transparent single-channel PEMWE. Arrows indicate water inlet and outlet. The AE sensor is shown at the upper location. (b) Electrochemical performance of the cell plotted as voltage against current density. 
iridium/ruthenium oxide on the anode side, was used (ITM Power, UK). The electrolyser was operated with a water inflow temperature of $50^{\circ} \mathrm{C}$, which is within the range of commonly applied temperatures in the literature $[5,6]$. Water flow rate ranged from $5 \mathrm{ml} \mathrm{min}^{-1}$ to $30 \mathrm{ml} \mathrm{min}^{-1}$, which translates into a water ratio [44] between 4 and 24 at $2 \mathrm{~A} \mathrm{~cm}^{-2}$. A potentiostat (Gamry Reference 3000 Galvanostat/Potentiostat with a Gamry 30k Booster; Gamry Instruments, USA) was used for electrochemical testing at a current density $i$ ranging from 0 to $2 \mathrm{~A} \mathrm{~cm}^{-2}$.

\subsection{Acoustic Emission}

The acoustic emission of the PEMWE was monitored using a piezoelectric sensor (S9208; Mistras NDT, UK). The signal was filtered and pre-amplified by $26 \mathrm{~dB}$ and a digital node extracted an acoustic hit from the continuous signal whenever the noise threshold of $37 \mathrm{~dB}$ was exceeded. For each data point, acoustic data was recorded over the course of 1 minute during galvanostatic operation of the PEMWE cell. The AE sensor was installed on the anode side, with two different locations investigated. The lower point of interest was located $1.5 \mathrm{~cm}$ from the start of the flow channel near the inlet; the upper location $1.5 \mathrm{~cm}$ from the top of the channel near the outlet. These two distinct locations were chosen as to represent markedly different flow regimes as typically $400 \%$ more gas has to pass through the upper location. Acoustic signals arising from the cathode are a potential source of error; however, it is unlikely that a significant magnitude of acoustic signal can pass through the various acoustic impedances from the cathode to the anode side. This is especially significant for the interface between anode LGDL and flow channel, which would need to be passed by any signal from the cathode side. As this is a solid/liquid interface, it is likely that up to $90 \%$ of signal are reflected [45].

\subsection{Acoustic Emission Post-processing}

Data collection and analysis was performed using the commercial software AEWin (Physical Acoustics). The number of acoustic hits over time, the corresponding average frequency of hits and their average amplitude were recorded. An acoustic hit is registered whenever the amplitude of the acoustic signal exceeds a certain predefined threshold; it ends when the signal has permanently 
damped back below the threshold. The hit rate $H$ is defined as acoustic hits per unit time. When the signal associated with an acoustic hit is analysed by fast Fourier transform (FFT) or similar techniques, a characteristic peak frequency is obtained. By averaging the peak frequency of all hits occurring within one sampling period, the average peak frequency $f$ is obtained. This is the frequency of the voltage-time profile of a specific AE hit averaged over all hits; it is not the frequency with which hits occur over time. Various studies have established that bubble oscillations cause pressure impulses at a frequency specific to bubble size, which can be picked up by $A E[30,46-48]$. For free oscillation of a bubble in a liquid the following correlation between oscillation-free bubble radius $R_{0}$ and its oscillation frequency $f$ can be found [49]:

$$
f=\frac{1}{2 \pi} \sqrt{\frac{3 \kappa p_{\infty}}{\rho R_{0}^{2}}-\frac{2 \sigma}{\rho R_{0}^{3}}}
$$

where $\kappa$ is the polytropic coefficient, $p_{\infty}$ is the pressure at a point in the liquid far away from the bubble, $\rho$ is the density of the liquid and $\sigma$ is the surface tension between liquid and gas. For systems similar to air-water the surface tension is negligible and one obtains [30]:

$$
f=\frac{1}{2 \pi} \sqrt{\frac{3 \kappa p_{\infty}}{\rho R_{0}^{2}}}
$$

which illustrates that the frequency of oscillation is inversely proportional to bubble size. Even though bubbles in the flow channel of an electrolyser do not freely oscillate, an analogous relationship between bubble size and frequency for the collision between bubbles (or the collision between bubbles with the end plate or wall) may exist.

Finally, the mean value of the maximum amplitude of all AE hits is the average peak amplitude $A$. The magnitude of each hit amplitude is determined by the pressure impulse, emitted by the acoustic event. In the case of a multitude of bubbles oscillating at the same time the resulting pressure pulse $p_{\text {res }}$ directly scales with the number of bubbles $N$ and the pressure impulse $p$ emitted by one bubble [30]: 


$$
p_{\text {res }}^{2}=N p^{2}
$$

\subsection{High-Speed Imaging}

A high-speed camera (Photron FASTCAM SA1) was used for imaging of the flow channel. Images were taken at 2000 frames per second and a resolution of $1024 \times 1024$ pixels over the course of $5.46 \mathrm{~s}$ (maximum available acquisition time at this frame rate) for each set of experimental conditions. A temporal resolution of 2000 frames per second was chosen to ensure no feature of the flow was missed, and the evolution of flow regime along the channel could be observed with high temporal detail. This resulted in 10920 images for each set of conditions, which offers a large set of data for quantitative analysis. After normalising with an image of the channel during pure water flow, images were then processed to calculate the number and size of captured bubbles (Figure 3 (a)-(d) for bubbly flow and (e)-(h) for slug flow).
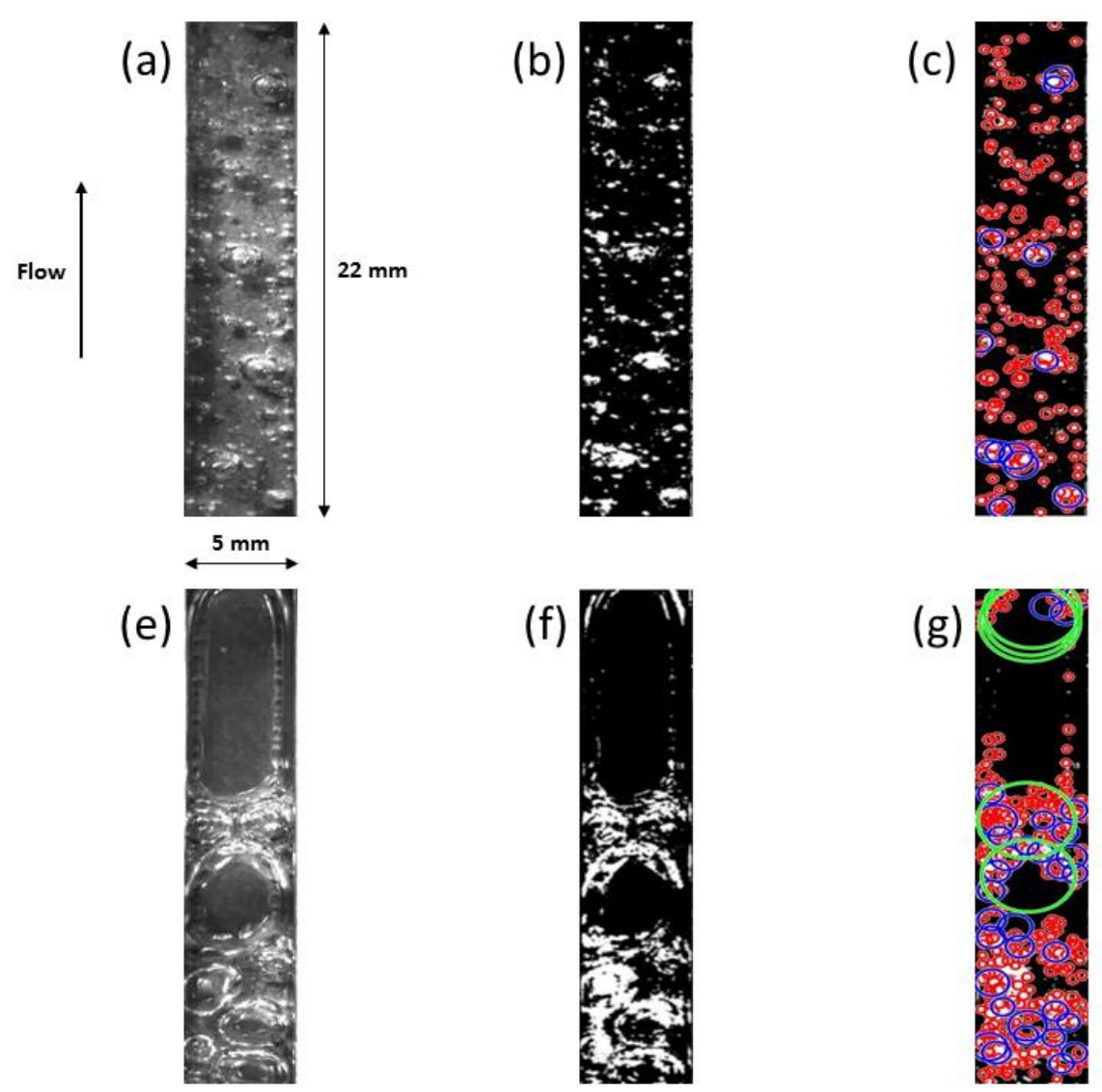

(d)
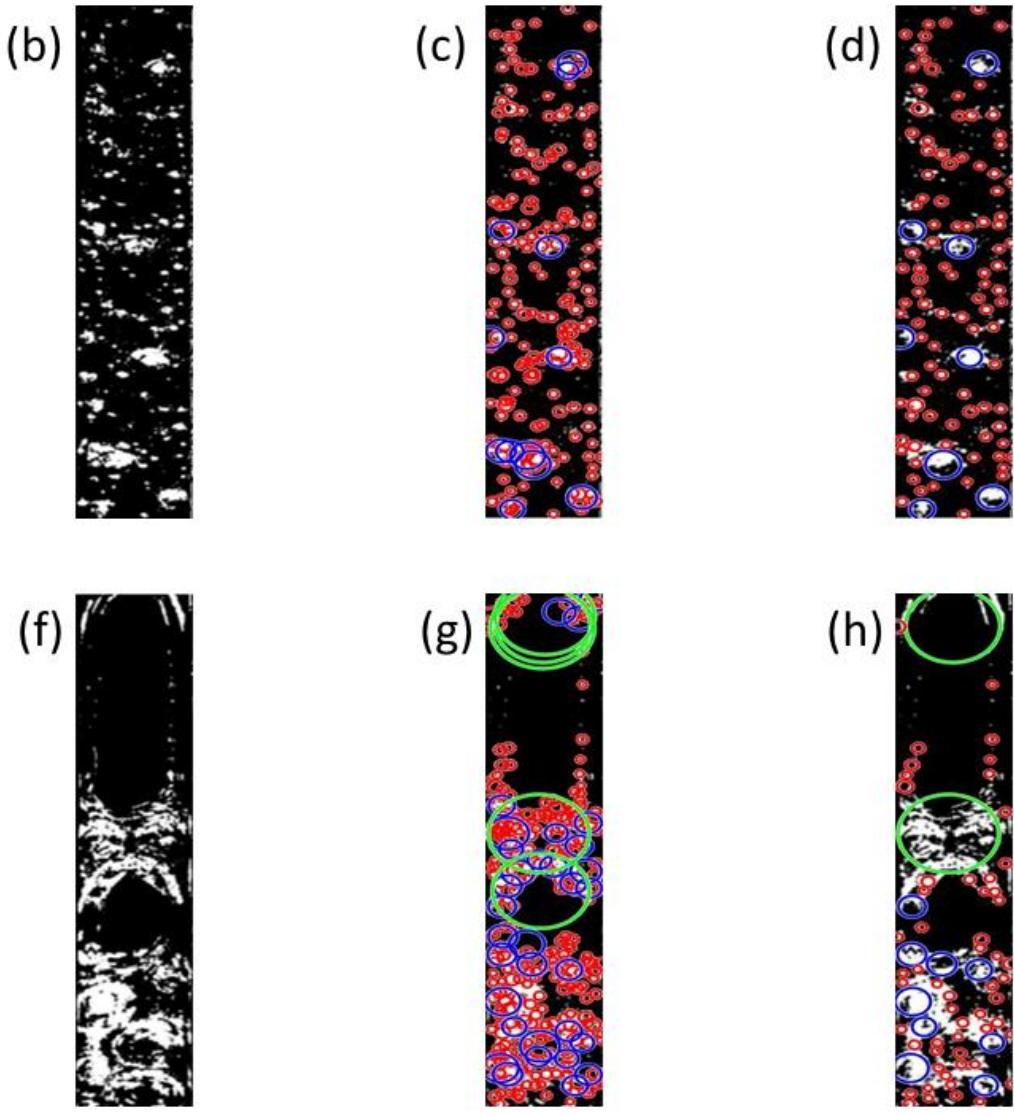

(h)

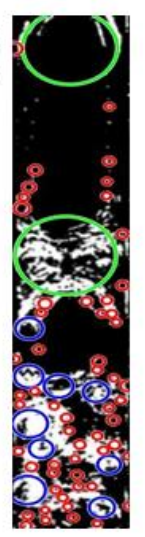

Fig. 3. Illustration of the use of the algorithm for analysis of bubbly (a-d) and slug (e-h) flow. Raw images (a, e) are thresholded and filtered $(b, f)$, circular structures are identified $(c, g)$ and finally, overlapping circles are removed $(d, h)$. 
The images used for this analysis were high-resolution images of the region where the AE sensor was placed, taken with a Tokina MACRO 100 F2.8 D lens (spatial resolution $50 \mu \mathrm{m}$ ), whereas the whole length of the flow channel was captured with a Sigma 1:2.8 DG HSM lens (spatial resolution $300 \mu \mathrm{m}$ ).

\subsection{Image Post-processing}

MATLAB (MathWorks) was used to perform all necessary post-processing steps. First, images were limited to the channel region around the location of the sensor (Figures 3 (a) and (e)) and thresholded into black and white representations. These images were then processed using a box filter with a kernel size of 5 . The result of thresholding and filtering (Figures $3(b)$ and (f)) was used to identify dark and bright circular structures within different size regions in the images, which is illustrated in Figures 3 (c) and (g). Finally, all circles overlapping each other were removed, only retaining the largest overlapping circle (Figures $3(\mathrm{~d})$ and $(\mathrm{h})$ ). Size $D$ and number $N$ of bubbles were then averaged for all images within one set of conditions. The lower detection limit for this algorithm is a diameter of 5 pixels, equalling $125 \mu \mathrm{m}$. The process is limited to circular bubbles, which means that in case of elliptic slug bubbles only the length of the minor axis of the bubble is registered. To reduce computation time, only every $10^{\text {th }}$ image was used for data analysis. The resulting number of more than 1000 analysed images is sufficient for representative analysis. To make sure the algorithm produces trustworthy results, bubble size and number were also determined manually over the current density range for a water flow rate of $5 \mathrm{ml} \mathrm{min}{ }^{-1}$, by counting and measuring gas bubbles in seven randomly selected images for each current density. In case of non-spherical gas bubbles, the size of the bubble was taken as the length of the minor axis.

\section{Results}

The typical characteristics of acoustic emission in the single-channel cell are shown in Figure 4 for different flow rates over a range of current density at both sensor locations. For the upper location, the number of hits (Figure 4 (a)) rapidly increases initially and reaches a maximum at around $0.5 \mathrm{~A} \mathrm{~cm}^{-}$

2. The number of hits then decreases and reaches a plateau at approximately $1.5 \mathrm{~A} \mathrm{~cm}^{-2}$. For low 
(a)

Upper Location

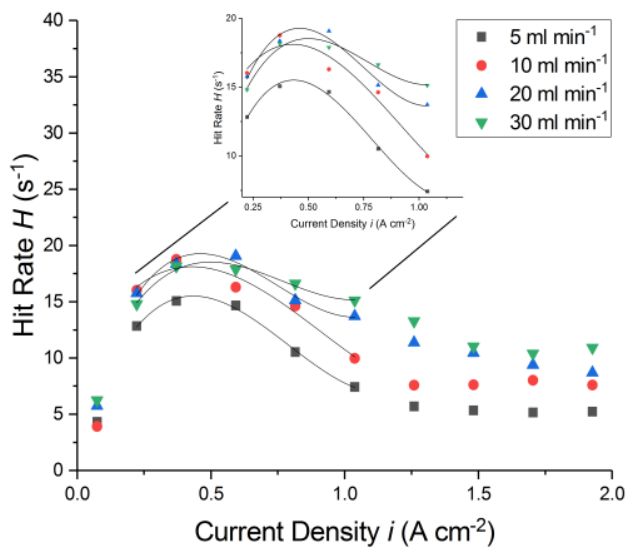

(b)

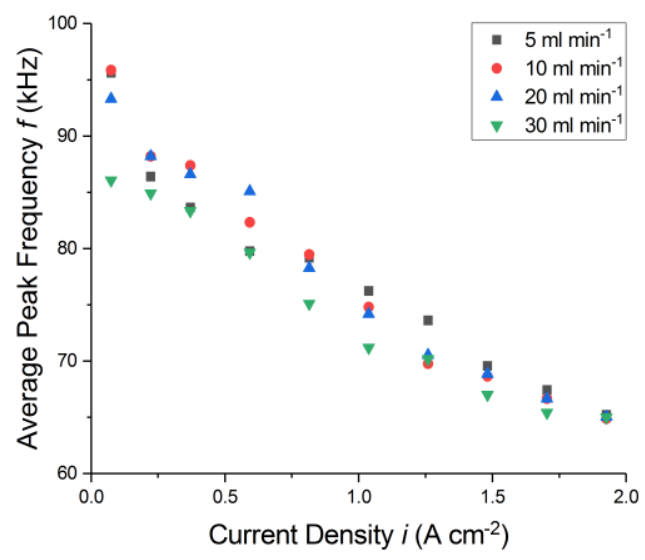

(c)

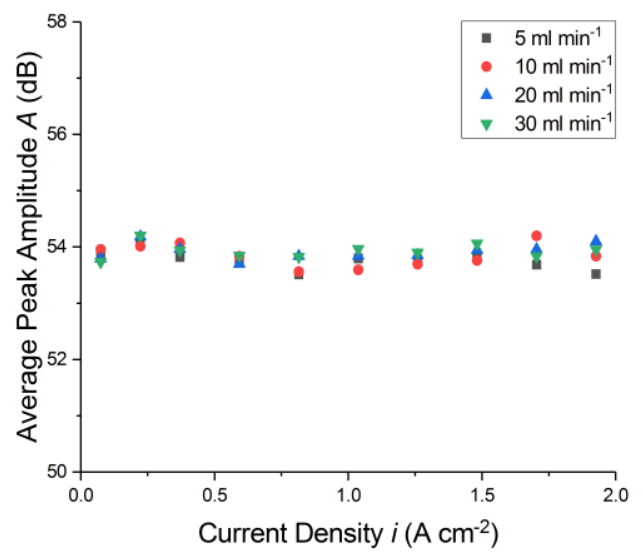

(d)

Lower Location

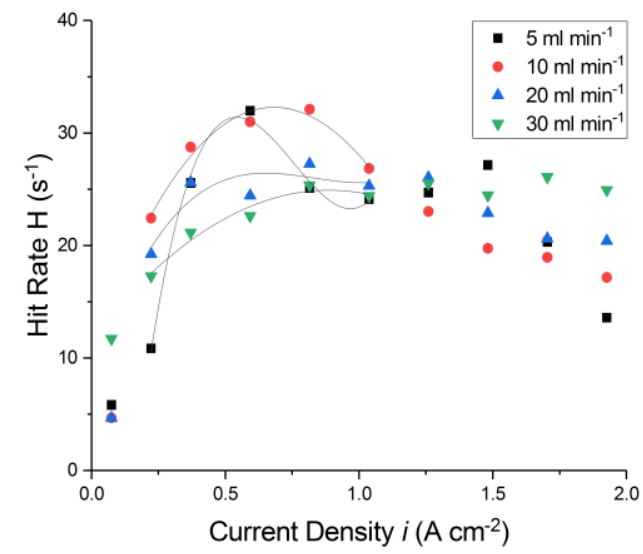

(e)

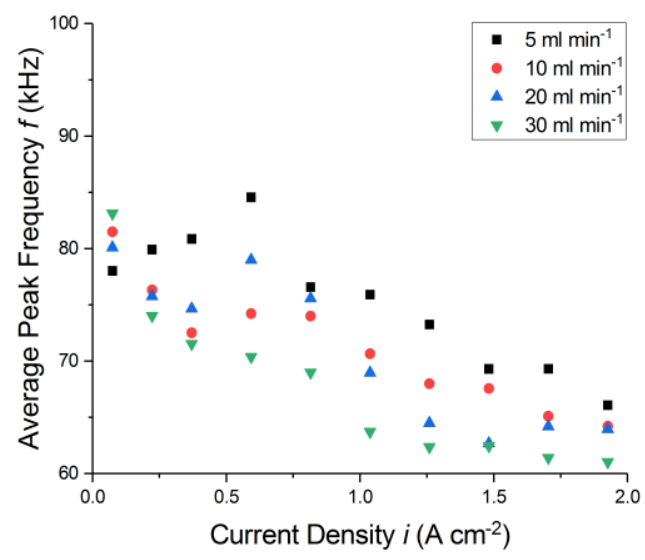

(f)

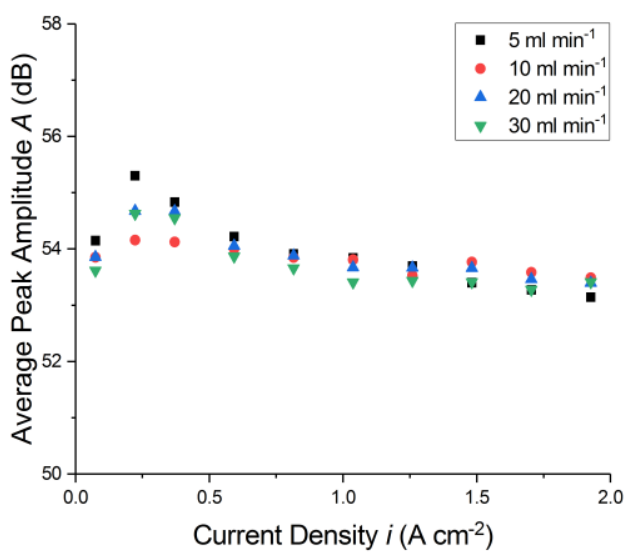

Fig. 4. Hit rate $(a, d)$, hit frequency $(b, e)$ and hit amplitude $(c, f)$ of acoustic emission at the upper (a-c) and lower (d-f) sensor location. The inset in (a) shows the region around the peak in more detail.

current densities $\left(<0.5 \mathrm{~A} \mathrm{~cm}^{-2}\right)$, the water flow rate has a negligible influence, whereas above this value the number of hits is a clear function of flow rate, reaching values of 5 hits per second at $5 \mathrm{ml}$ $\mathrm{min}^{-1}$ and 12 hits per second at $30 \mathrm{ml} \mathrm{min}-1$. This provides a correlation between flow processes in the 
electrolyser and its acoustic emission. In contrast, at the lower channel location the peak is less pronounced (Figure $4(\mathrm{~d})$ ), with the peak value at different current densities ranging from $0.5 \mathrm{~A} \mathrm{~cm}^{-2}$ to $0.8 \mathrm{~A} \mathrm{~cm}^{-2}$, and a much less prominent decrease in number of hits at higher current densities.

Figures 4 (b) and (e) illustrate the average peak frequency of AE hits as a function of current density. As discussed in Section 2.3, the frequency of bubble oscillation is linked to bubble size. Hence, the results from Figures 4 (b) and (e) imply a constant increase in bubble size at both the upper and lower locations, as the mass of oxygen produced increases with current density. However, the frequency decreases by $14.5 \mathrm{kHz}\left(\mathrm{A} \mathrm{cm}^{-2}\right)^{-1}$ for the upper location, but only $9 \mathrm{kHz}\left(\mathrm{A} \mathrm{cm}^{-2}\right)^{-1}$ for the lower location. Again, this is in line with expectation as for the upper location approximately $400 \%$ more gas is passing through the flow channel and therefore relative changes in bubble size between low and high current density are expected to be more pronounced.

At the same time, it can be seen from Figures 4 (c) and (f) that the average amplitude of AE hits is relatively independent of current density for both locations, as the value of $A$ only varies within one decibel. If the number of bubbles is expected to change when varying current density, this would lead to a changing amplitude of the AE signal (Equation 3 ) if it is assumed that the acoustic hits are emitted as a consequence of simultaneous oscillations. Hence, the invariance of amplitude implies that the signal does not originate in the simultaneous oscillation of bubbles, but in discrete, separate events such as the collision of bubbles with the end plate or channel wall of the electrolyser.

This leads us to propose a model of the origin of the acoustic emission signal in the observed system. Bubbles of different sizes move through the flow channels, which, depending on the depth of the flow channel relative to their size, float freely or impinge on the walls of the channel. The collision between bubble and wall leads to deformation of the bubble. Consequently, the bubble oscillates around its original shape with a frequency specific to its size. This causes an acoustic perturbation, which is transferred into the back plate and travels towards the other side of the plate where it is registered by the $A E$ sensor. 
(a)

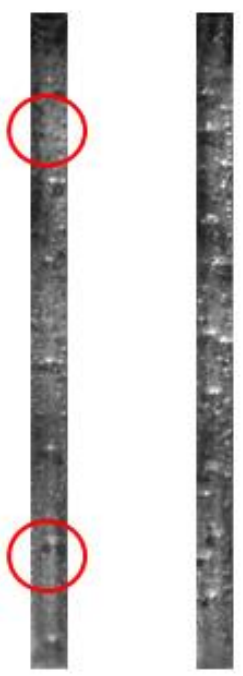

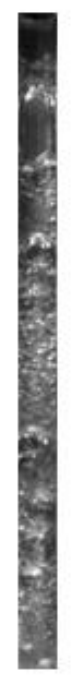

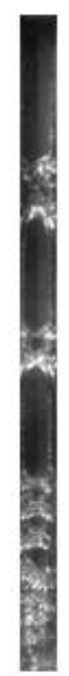

(b)
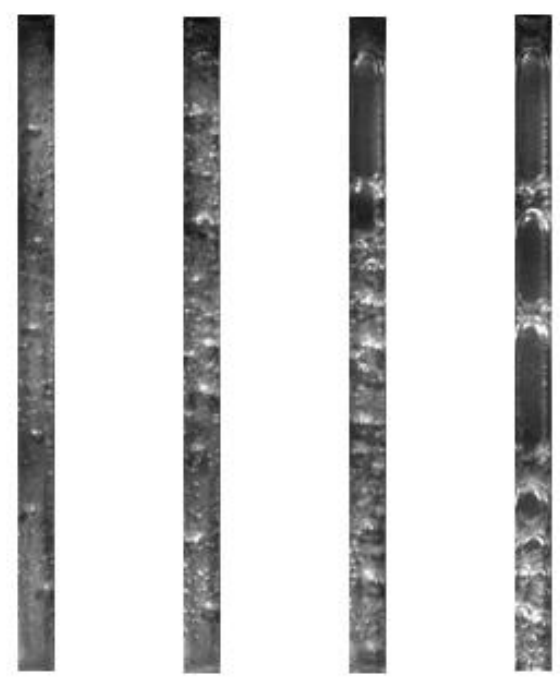

$0.07 \mathrm{~A} \mathrm{~cm}^{-2} \quad 0.37 \mathrm{~A} \mathrm{~cm}^{-2} 0.81 \mathrm{~A} \mathrm{~cm}^{-2} 1.93 \mathrm{~A} \mathrm{~cm}^{-2}$

$0.07 \mathrm{~A} \mathrm{~cm}^{-2}$

$0.37 \mathrm{~A} \mathrm{~cm}^{-2}$

$0.81 \mathrm{~A} \mathrm{~cm}^{-2} 1.93 \mathrm{~A} \mathrm{~cm}^{-2}$
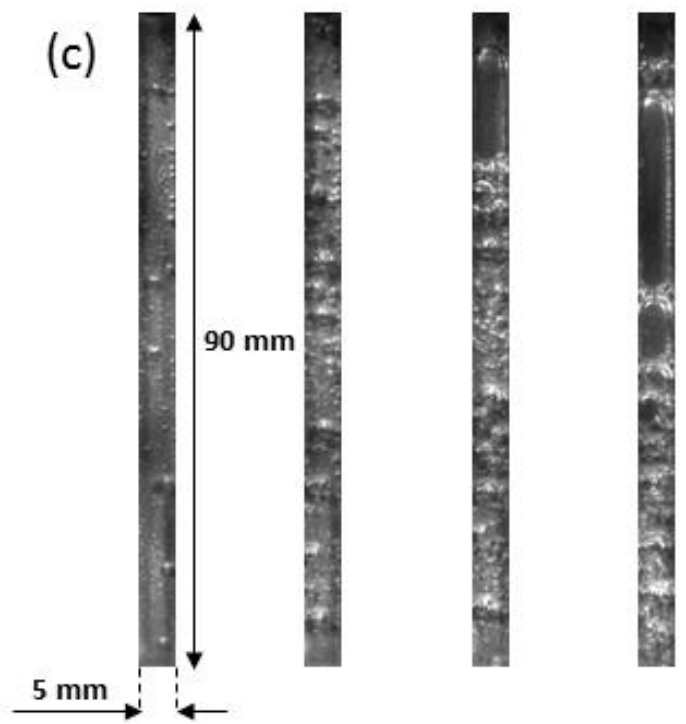

(d)
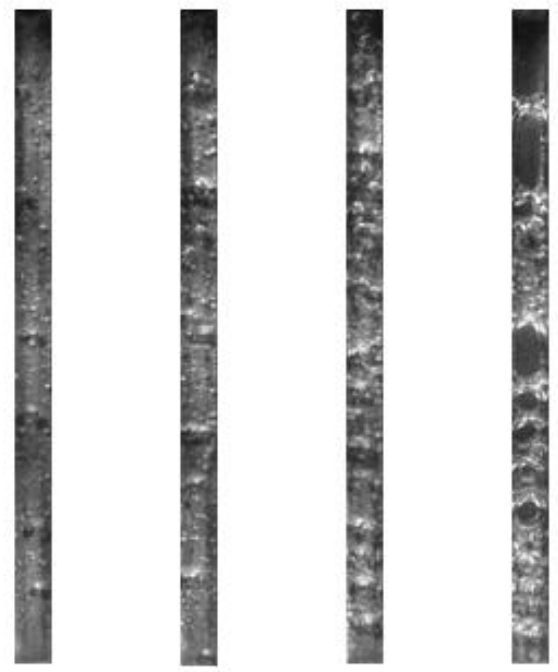

Fig. 5. High-speed imaging of the flow channel over a range of current densities at (a) $5 \mathrm{ml} \mathrm{min}{ }^{-1}$, (b) $10 \mathrm{ml} \mathrm{min}^{-1}$, (c) $20 \mathrm{ml}$ $\mathrm{min}^{-1}$ and (d) $30 \mathrm{ml} \mathrm{min}^{-1}$. Upper and lower sensor location are indicated by the red circles in (a).

To gain a better understanding of these processes, high-speed visual imaging of the flow channel was used. Figure 5 shows the entire length of the flow channel, with the upper and lower locations of the AE sensor indicated by red circles. Bubble size increases with current density; for $0.07 \mathrm{~A} \mathrm{~cm}^{-2}$ and 0.37 $\mathrm{A} \mathrm{cm}^{-2}$ the bubbly flow regime is predominant at both locations. For $0.81 \mathrm{~A} \mathrm{~cm}^{-2}$ and $1.93 \mathrm{~A} \mathrm{~cm}^{-2}$ slug flow is the dominant flow regime at the upper sensor location. At the lower sensor location, the regime is in the transition from bubbly to slug flow at $1.93 \mathrm{~A} \mathrm{~cm}^{-2}$. While images for the low current densities of $0.07 \mathrm{~A} \mathrm{~cm}^{-2}$ and $0.37 \mathrm{~A} \mathrm{~cm}^{-2}$ are similar for different flow rates, a general trend towards elongation 
of slugs with decreasing flow rate can be observed at high current densities. To quantify this effect, the algorithm described in Section 2.5 and Figure 3 was used to calculate bubble sizes and numbers for the regions around the AE sensor as shown in Figure 6.

For both locations, at the lowest current density at $0.07 \mathrm{~A} \mathrm{~cm}^{-2}$, bubble numbers are up to $140 \%$ higher than for the other current densities. However, for all other current densities, especially at the upper location, the development of the number of bubbles over current density follows the same trend as the number of acoustic hits (Figure 4 (a)); a steep incline is followed by a decline for current densities higher than $0.5 \mathrm{~A} \mathrm{~cm}^{-2}$ which ends in a plateau for high current densities. Although the trend is not as clear for the lower location, a correlation between AE (Figure 4 (d)) and high-speed imaging data can be observed. This indicates a qualitative correlation between the number of bubbles and acoustic hits and supports the conclusion made above that the acoustic emission observed originates from the collision of bubbles with the channel walls. The data from manual counting of bubbles shows that the algorithm overestimates the number of bubbles; however, the trend with current density is qualitatively very similar.

The results from manual counting show the same deviation in bubble number for low current densities as that determined from high-speed imaging. Hence, from $0.07 \mathrm{~A} \mathrm{~cm}^{-2}$ to $0.22 \mathrm{~A} \mathrm{~cm}^{-2}$ a multitude of small bubbles are produced, which due to the low energy associated with their vibration are not able to produce an acoustic perturbation strong enough to be observed in the experimental setup.

The size of bubbles in the flow channel changes with current density (6 (c) and (d)). For the upper location an increase in average bubble size between 30-50 \% from lowest to highest current density is observed. Again, the trend for the lower location is less pronounced, although an overall increase in bubble size with current density is apparent. This supports the above findings, as the frequency of AE decreases with increasing current density (Figures 4 (b) and (e)). Hence, the notion that acoustic emission is a suitable technique to observe the evolution of bubble size in the flow channels is strengthened. As the change in the size of bubbles is caused by a change in current density, AE can 
potentially be used to monitor global or local current densities. Comparison with the manually obtained bubble size shows that the true size is not captured accurately by the algorithm. However, this paper is concerned with detecting qualitative changes and the increasing trend in bubble size is correctly identified by the algorithm.

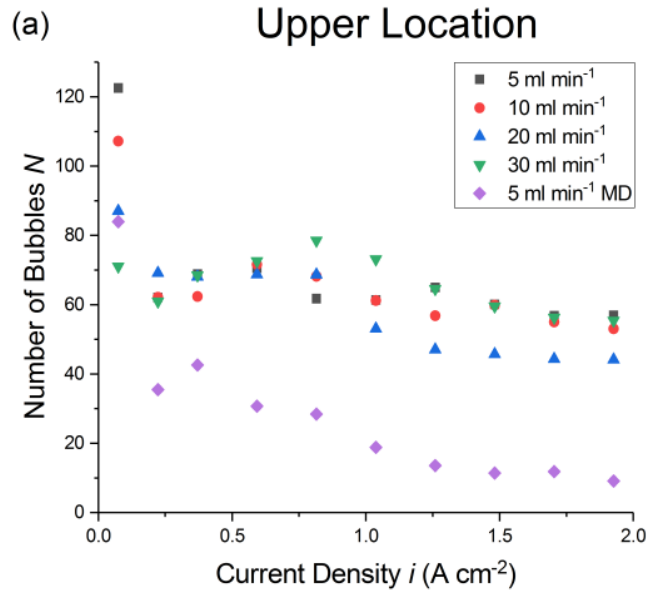

(c)

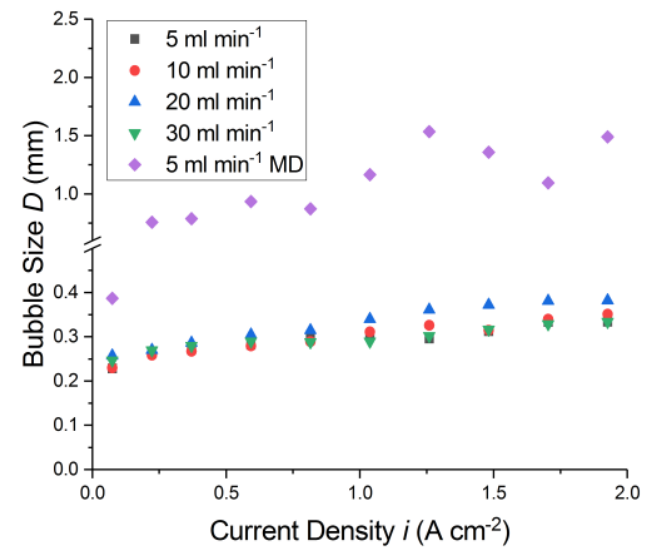

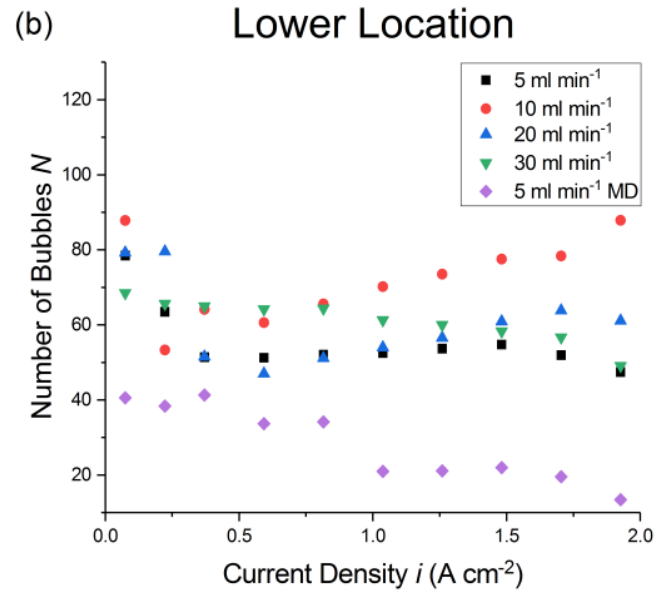

(d)

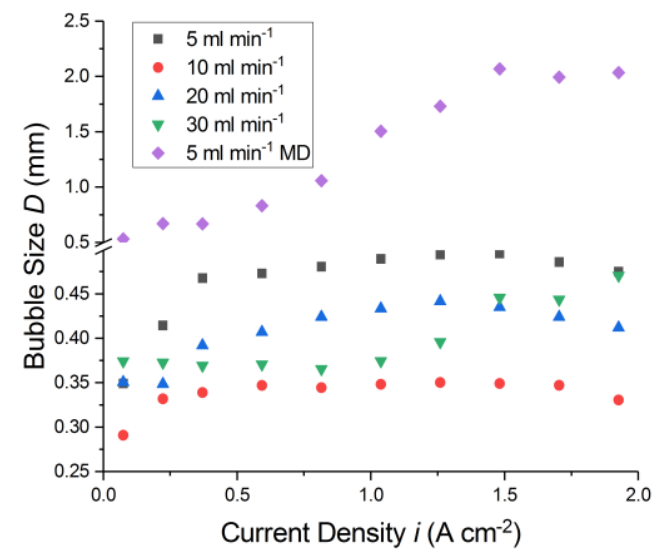

Fig. 6. Number $(a, b)$ and size ( $c, d)$ of bubbles extracted from high-speed imaging for the upper (a, c) and lower (b, d) sensor location. Manually determined (MD) values added for comparison.

To investigate the relationship between flow regime and acoustic emission signal, a flow regime map was developed. This requires knowledge of water and gas flow in the electrolyser cell. Assuming that the water at the inlet is completely gas free, the only gas in the flow channels of the anode will be the oxygen produced by the reaction. The mass of oxygen $G_{O 2}$ at the outlet of the flow channel can be calculated as [44]: 


$$
G_{O 2}=\frac{i A M_{O 2}}{4 F n_{\text {chan }} a}
$$

where $i$ is the current density, $A$ is the active area of the electrolyser, $M_{O 2}$ is the molecular mass of oxygen, $F$ is the Faraday constant, $n_{\text {chan }}$ is the number of flow channels and $a$ is the cross-sectional area of the flow channel. Values for all constants used in these calculations can be found in Table 1.

Tab. 1. Values used for calculation.

\begin{tabular}{c|c} 
Constant & Value \\
\hline$M_{O 2}\left(\mathrm{~kg} \mathrm{~mol}^{-1}\right)$ & $32 \cdot 10^{-3}$ \\
$M_{H 2 O}\left(\mathrm{~kg} \mathrm{~mol}^{-1}\right)$ & $18 \cdot 10^{-3}$ \\
$\rho_{O 2}\left(\mathrm{~kg} \mathrm{~m}^{-3}\right)$ & 1.33 \\
$\rho_{H 2 O}\left(\mathrm{~kg} \mathrm{~m}^{-3}\right)$ & 972 \\
$A\left(\mathrm{~cm}^{2}\right)$ & 13.5 \\
$F\left(\mathrm{C} \mathrm{mol}^{-1}\right)$ & $9.65 \cdot 10^{4}$ \\
$n_{\text {chan }}$ & 9 \\
$a\left(\mathrm{~cm}^{2}\right)$ & 0.15
\end{tabular}

Similarly, the amount of water consumed by the reaction on the anode side is expressed by [44]:

$$
G_{\text {cons }}=\frac{i A M_{H 2 O}}{2 F n_{\text {chan }} a}
$$

with the molecular mass of water $M_{H 2 O}$.

In addition to the water reacting in the oxygen evolution reaction, a considerable amount of water is also transported through the PEM membrane to the cathode side. This electro-osmotic drag is caused by water molecules being dragged by protons migrating to the cathode side, according to [44]:

$$
G_{\text {drag }}=n_{\text {drag }} \frac{i A M_{H 2 O}}{F n_{\text {chan }} a}
$$

The electro-osmotic drag coefficient $n_{d r a g}$ expresses how many water molecules are transported for one proton. Its value is dependent on the temperature $T$ and has been experimentally determined as [50]: 


$$
n_{\text {drag }}=0.0134 T+0.03
$$

With knowledge of the above quantities and the amount of water circulated into the electrolyser $G_{\text {circ }}$, the gas fraction $x$ within the flow channels can be calculated. To calculate values for a point along the flow channel which is not the outlet, it is necessary to reduce the active area $A$ used for calculation respectively [44].

$$
x=\frac{G_{O 2}}{G_{\text {circ }}-G_{\text {cons }}-G_{\text {drag }}+G_{O 2}}
$$

This can then be used to determine the flow rate of liquid $j_{l}$ and gas $j_{g}$ using the densities of water $\rho_{\mathrm{H} 2 \mathrm{O}}$ and oxygen $\rho_{\mathrm{O} 2}$ and the total flow $G$, which is the sum of gas and liquid flow [44]:

$$
\begin{gathered}
j_{l}=\frac{G(1-x)}{\rho_{H 2 O}} \\
j_{g}=\frac{G x}{\rho_{O 2}}
\end{gathered}
$$

The above procedure defines the position of a point of operation in a flow regime map. Cubaud et al. [14] have provided a flow regime map for air in water flowing through square microchannels with a width of several hundred micrometers. Although this configuration is not identical to that of the anode side of a PEMWE, the material parameters for air are similar to those of oxygen. Another limitation is that the flow channel in Cubaud's study was a horizontally oriented, single-serpentine channel, whereas this work uses a vertically oriented single channel. Nevertheless, by using this flow map to check the flow regime at different points of operation of the PEMWE used in this work, valuable insights into the relation between acoustic emission and flow regime can be obtained.

The flow regime map for upper and lower sensor locations (Figures 7 (b) and (c)) at all points of operation examined in this work covers all flow regimes from bubbly to dry flow (Figure 7 (a)). The amount of gas produced increases with current density, which results in higher bubble speeds. Simultaneously, the water flow rate decreases with current density but is mainly dependent on the 
(a)

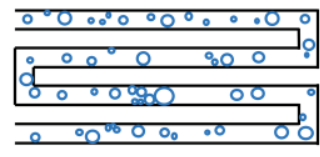

Bubbly

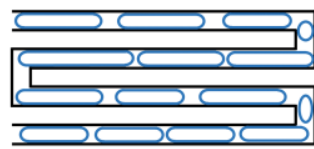

Wedging

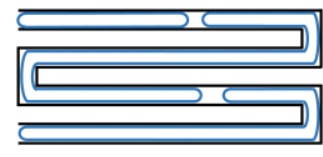

Slug
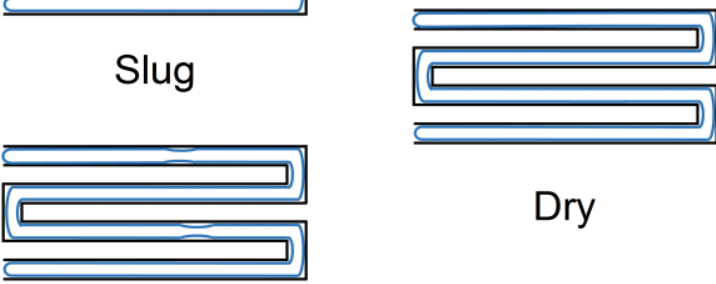

Dry

\section{Annular}

(b)

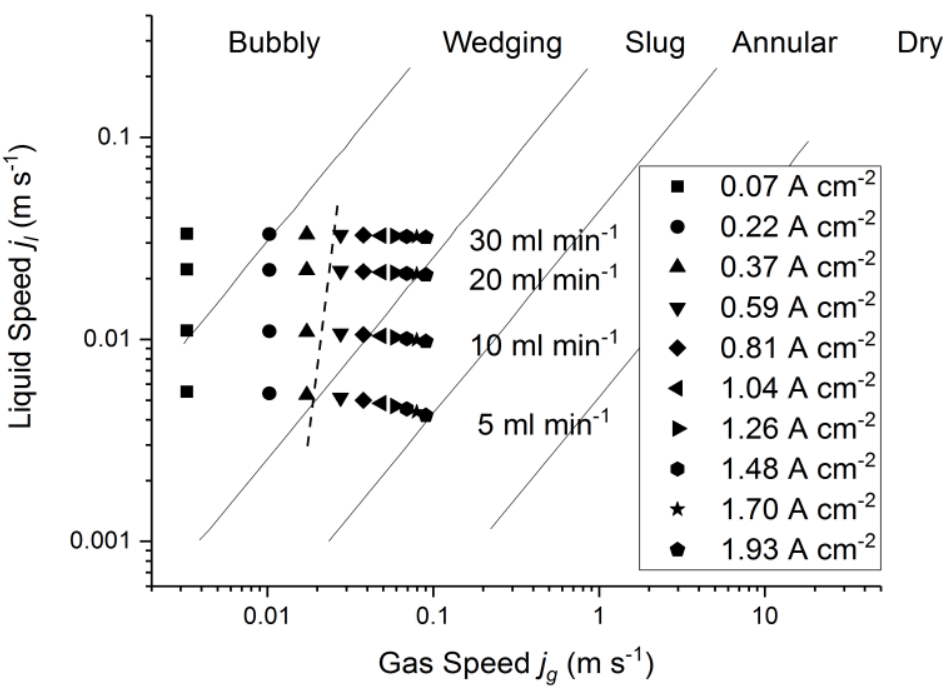

(c)

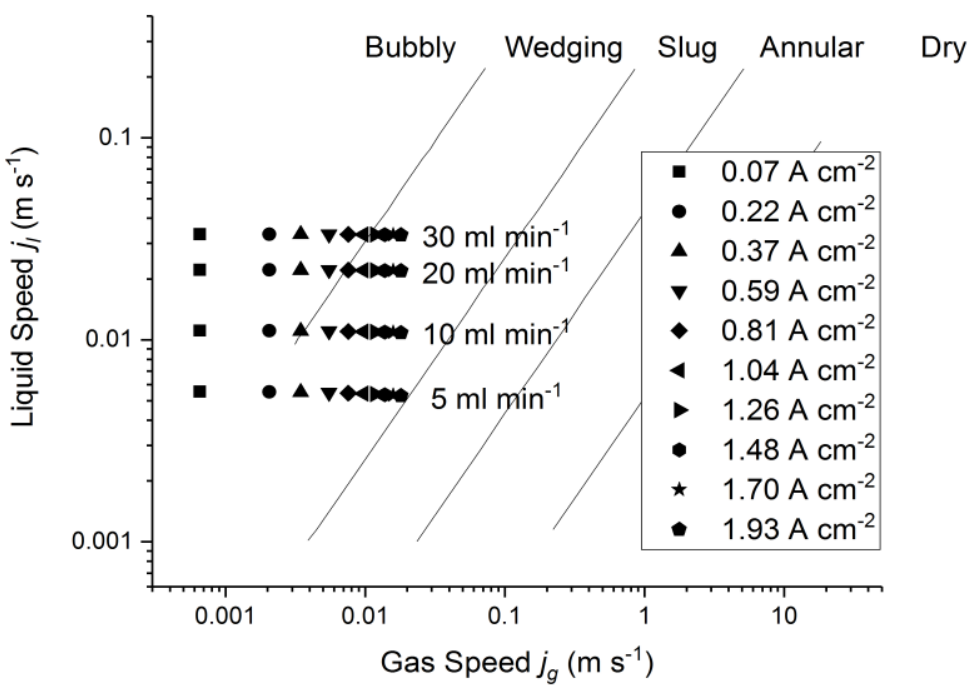

Fig. 7. (a) Flow regimes as defined by Cubaud et al. [14]. Flow regime maps for the upper (b) and lower (c) sensor locations. The dashed line in Figure 7 (b) marks the transition between bubbly and slug flow as indicated by acoustic emission. 
amount of water circulated $G_{c i r c}$. As the current density increases, the flow regime undergoes a series of transitions, initially from the bubbly regime via the wedging regime to the slug regime. When the slug bubbles have almost interconnected, the annular regime is reached, which then transitions into the dry regime. It is evident (Figure $7(a)$ ) that the wedging regime is a transitory regime between bubbly and slug flow and is specific to Cubaud's [14] work. Hence it can be assumed that the transition between bubbly and slug flow in the system investigated in this work lies within the wedging regime. For the upper location, points of operation range from the bubbly flow regime up to the transition between slug and annular flow, while for the lower location the boundary between wedging and slug flow is only reached for the lowest water flow rate of $5 \mathrm{ml} \mathrm{min}$. range of flow regimes is much wider for the upper location (Figure 5).

As illustrated above, the number of acoustic hits is linked to the number of bubbles flowing through the flow channel of the electrolyser. With increasing current density, the bubble size initially increases to accommodate the surplus of gas produced by the reaction. At a certain point the available space is almost completely filled with discrete gas bubbles and further gas production results in coalescence of bubbles. Therefore, the maximum number of gas bubbles is observed at the transition between bubbly and slug flow regime. This offers a possibility to use AE to detect the change from bubbly to slug flow. To illustrate this capability, Figure 8 shows the location of the peak on the current density axis of Figure 4 (a) against the flow rate of circulated water for the upper location. The peak locations were taken from the regression around the maxima of the curves in Figure 4 (a). A cubic regression was chosen to account for the asymmetrical peak shape. The maximum of the acoustic hits is shifted towards higher current densities with increasing water flow rate; an increase of $0.0027\left(\mathrm{~A} \mathrm{~cm}^{-2}\right)(\mathrm{ml}$ $\left.\min ^{-1}\right)^{-1}$ in the peak location is observed. The transition into slug flow is favoured by low water flow rates (Figure 5), as this reduces the water-to-gas ratio.

To further illustrate how acoustic emission can diagnose the regime within the flow channels of a PEMWE, the peak locations from Figure 8 were connected by a dashed line in Figure 7 (b). This line represents the transition between bubbly and slug flow for the upper sensor location, as determined 
from AE. For the range of water flow rates investigated in this work the predicted change to slug flow falls within the wedging regime, which is a transitory regime between bubbly and slug flow. The gradient of the regime boundary is different from that observed in Cubaud's flow map; however, this is not surprising as the examined systems are not identical. The way in which changes to the experimental system can affect the shape and location of regime boundaries can be seen by comparing flow regime maps of different authors for similar systems [14,51].

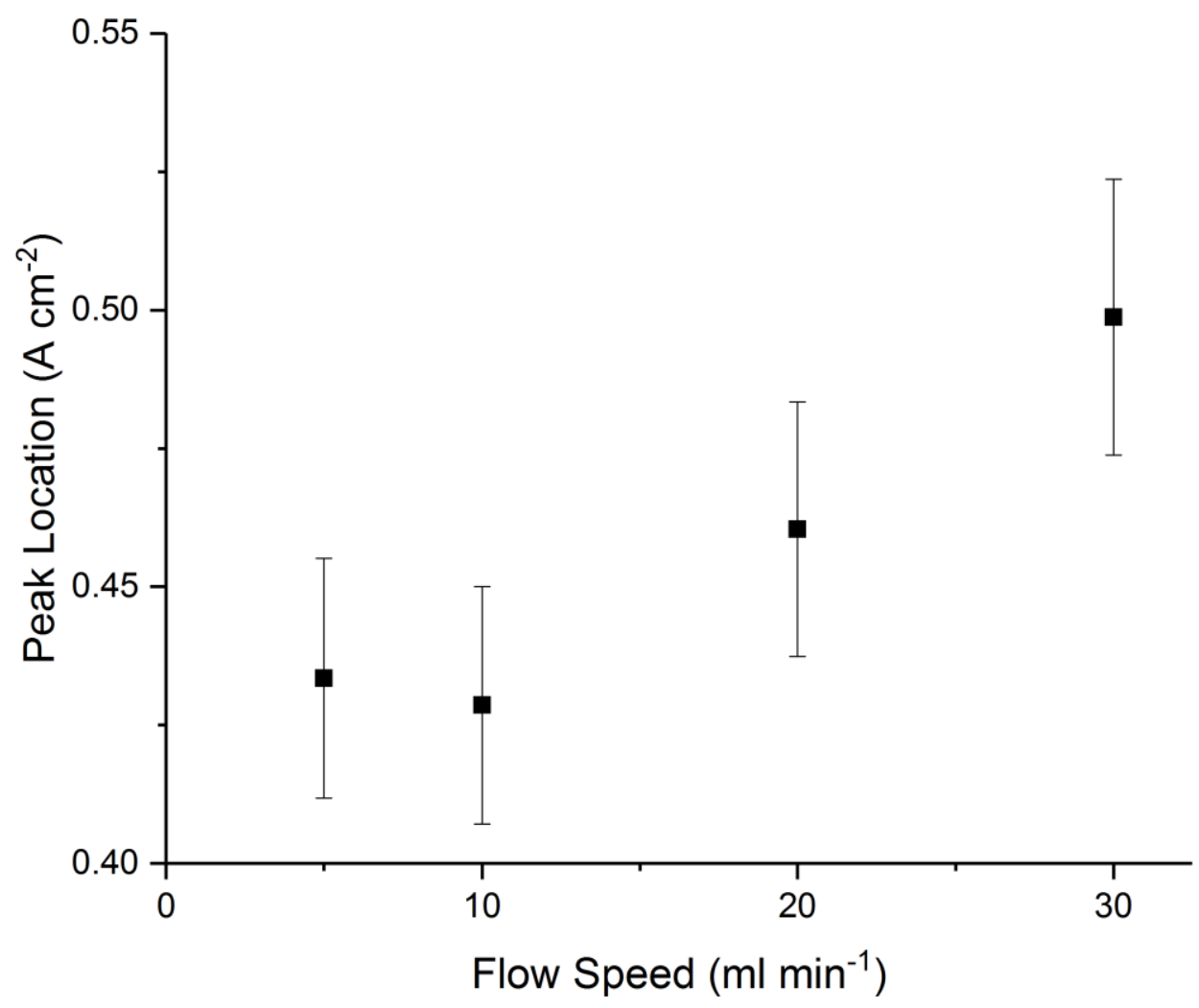

Fig. 8. Current density at which the maximum number of acoustic hits was registered as a function of water flow rate, which indicates the transition from bubbly to slug flow.

\section{Conclusion}

In this work we have successfully demonstrated the potential of acoustic emission as a diagnostic tool for PEMWE; in particular to study two-phase flow within the flow channels during gas formation. A close link between bubble size and number within the flow channel of a PEM water electrolyser and 
the AE measured on the surface of the end plates has been established. Two locations along the flow channel have been investigated via AE measurements and high-speed imaging. For the upper location, AE measurements showed that the number of acoustic hits reaches a maximum around $0.5 \mathrm{~A} \mathrm{~cm}^{-2}$ and decreases to a plateau at higher current densities. The average frequency of these hits decreases with current density, which can be attributed to an increase in average bubble size. High-speed imaging at the upper location is consistent with the acoustic emission results. The number of bubbles detected follows the same trend as the number of acoustic hits with current density. This implies that AE can monitor relative changes in the number of bubbles flowing through an electrolyser and therefore can detect changes in flow regime. Image analysis also showed a trend towards increasing bubble size at higher current densities, which supports the frequency data from acoustic emission; hence, AE can be used to detect changes in bubble size in a PEM electrolyser. Similar trends were observed for the lower location; however, not as pronounced as for the upper location. This is consistent with smaller amounts of gas passing by the lower location, which causes the relative changes in bubble number and size to be less significant.

To further strengthen the link between acoustic emission and flow regime diagnosis, a flow map was invoked. The states of operation in the PEMWE for this study covered the range from bubbly flow to the onset of the annular regime. By analysing the current density at which the number of acoustic hits reaches its maximum, a regime boundary between bubbly and slug flow for the flow system used in this work was found. This regime boundary lies within the wedging regime, as defined by Cubaud et al. [14], which is a transitory regime between bubbly and slug flow. This supports the idea that the maximum of acoustic hits is found at the transition between the bubbly and the slug regime and hence implies that acoustic emission can be used to identify this regime change. As the number and size of bubbles in a PEMWE are consequences of local and global current density, AE offers novel insight into the electrochemical activity and flow characteristics of the system. The single channel system used in this work can be seen as the smallest repetitive unit of bigger PEMWE cells or stacks, which illustrates how AE can be applied to more advanced designs of industrial relevance. 


\section{Acknowledgements}

The authors acknowledge financial support into the EIL's hydrogen and fuel cell activity from the EPSRC through grants (EP/R023581/1; EP/P009050/1; EP/N032888/1; EP/M014371/1; EP/M009394; EP/L015749/1; EP/K038656/1). The authours would also like to acknowledge the Royal Academy of Engineering for funding Robinson through the UKIC Postgraduate Fellowship Scheme (ICRF1718\1\34). Support from the UK National Measurement System is also gratefully acknowledged. PRS acknowledges funding from the Royal Academy of Engineering (CiET1718\59).

\section{References}

[1] J.D. Holladay, J. Hu, D.L. King, Y. Wang, An overview of hydrogen production technologies, Catal. Today. 139 (2009) 244-260. doi:10.1016/j.cattod.2008.08.039.

[2] M. Carmo, D.L. Fritz, J. Mergel, D. Stolten, A comprehensive review on PEM water electrolysis, Int. J. Hydrogen Energy. 38 (2013) 4901-4934. doi:10.1016/j.ijhydene.2013.01.151.

[3] A. Buttler, H. Spliethoff, Current status of water electrolysis for energy storage, grid balancing and sector coupling via power-to-gas and power-to-liquids: A review, Renew. Sustain. Energy Rev. 82 (2018) 2440-2454. doi:10.1016/j.rser.2017.09.003.

[4] S.M. Saba, M. Müller, M. Robinius, D. Stolten, The investment costs of electrolysis - A comparison of cost studies from the past 30 years, Int. J. Hydrogen Energy. 43 (2018) 12091223. doi:10.1016/j.ijhydene.2017.11.115.

[5] Z. Kang, J. Mo, G. Yang, S.T. Retterer, D.A. Cullen, T.J. Toops, J.B. Green Jr, M.M. Mench, F.-Y. Zhang, Investigation of thin/well-tunable liquid/gas diffusion layers exhibiting superior multifunctional performance in low-temperature electrolytic water splitting, Energy Environ. Sci. 10 (2017) 166-175. doi:10.1039/C6EE02368A.

[6] I. Dedigama, P. Angeli, K. Ayers, J.B. Robinson, P.R. Shearing, D. Tsaoulidis, D.J.L. Brett, In situ diagnostic techniques for characterisation of polymer electrolyte membrane water electrolysers - Flow visualisation and electrochemical impedance spectroscopy, Int. J. Hydrogen Energy. 39 (2014) 4468-4482. doi:10.1016/j.ijhydene.2014.01.026.

[7] J. Seweryn, J. Biesdorf, T.J. Schmidt, P. Boillat, Communication-Neutron Radiography of the Water/Gas Distribution in the Porous Layers of an Operating Electrolyser, J. Electrochem. Soc. 163 (2016) F3009-F3011. doi:10.1149/2.0641607jes.

[8] O. Panchenko, E. Borgardt, W. Zwaygardt, F.J. Hackemüller, M. Bram, N. Kardjilov, T. Arlt, I. Manke, M. Müller, D. Stolten, W. Lehnert, In-situ two-phase flow investigation of different porous transport layer for a polymer electrolyte membrane (PEM) electrolyzer with neutron spectroscopy, J. Power Sources. 390 (2018) 108-115. doi:10.1016/j.jpowsour.2018.04.044.

[9] O.F. Selamet, U. Pasaogullari, D. Spernjak, D.S. Hussey, D.L. Jacobson, M.D. Mat, Two-phase flow in a proton exchange membrane electrolyzer visualized in situ by simultaneous neutron radiography and optical imaging, Int. J. Hydrogen Energy. 38 (2013) 5823-5835. doi:10.1016/j.ijhydene.2013.02.087.

[10] O.F. Selamet, U. Pasaogullari, D. Spernjak, D.S. Hussey, D.L. Jacobsen, M.D. Mat, In-situ twophase flow investigation of Proton Exchange Membrane (PEM) electrolyzer by simultaneous optical and neutron imaging, ECS Trans. 41 (2011) 349-362.

[11] M.A. Hoeh, T. Arlt, N. Kardjilov, I. Manke, J. Banhart, D.L. Fritz, J. Ehlert, W. Lüke, W. Lehnert, In-operando Neutron Radiography Studies of Polymer Electrolyte Membrane Water 
Electrolyzers, ECS Trans. 69 (2015) 1135-1140.

[12] H. Ito, T. Maeda, A. Nakano, C.M. Hwang, M. Ishida, N. Yokoi, Y. Hasegawa, A. Kato, T. Yoshida, Influence of Different Gas Diffusion Layers on the Water Management of Polymer Electrolyte Unitized Reversible Fuel Cell, ECS Trans. 33 (2010) 945-954. doi:10.1149/1.3484588.

[13] H. Ito, T. Maeda, A. Nakano, C.M. Hwang, M. Ishida, A. Kato, T. Yoshida, Experimental study on porous current collectors of PEM electrolyzers, Int. J. Hydrogen Energy. 37 (2012) 74187428. doi:10.1016/j.jijhydene.2012.01.095.

[14] T. Cubaud, C.M. Ho, Transport of bubbles in square microchannels, Phys. Fluids. 16 (2004) 4575-4585. doi:10.1063/1.1813871.

[15] C.W. Choi, D.I. Yu, M.H. Kim, Adiabatic two-phase flow in rectangular microchannels with different aspect ratios: Part i - Flow pattern, pressure drop and void fraction, Int. J. Heat Mass Transf. 54 (2011) 616-624. doi:10.1016/j.ijheatmasstransfer.2010.07.067.

[16] T.M. Roberts, M. Talebzadeh, Acoustic emission monitoring of fatigue crack propagation, J. Constr. Steel Res. 59 (2003) 695-712. doi:10.1016/S0143-974X(02)00064-0.

[17] A. Nair, C.S. Cai, Acoustic emission monitoring of bridges: Review and case studies, Eng. Struct. 32 (2010) 1704-1714. doi:10.1016/j.engstruct.2010.02.020.

[18] F. Bellenger, H. Mazille, H. Idrissi, Use of acoustic emission technique for the early detection of aluminum alloys exfoliation corrosion, NDT E Int. 35 (2002) 385-392. doi:10.1016/S09638695(02)00011-7.

[19] C. Jomdecha, A. Prateepasen, P. Kaewtrakulpong, Study on source location using an acoustic emission system for various corrosion types, NDT E Int. 40 (2007) 584-593. doi:10.1016/j.ndteint.2007.05.003.

[20] T. Ohzuku, H. Tomura, K. Sawai, Monitoring of Particle Fracture by Acoustic Emission during Charge and Discharge of Li/MnO2 Cells, J. Electrochem. Soc. 144 (1997) 3496-3500. doi:10.1149/1.1838039.

[21] K. Rhodes, N. Dudney, E. Lara-Curzio, C. Daniel, Understanding the Degradation of Silicon Electrodes for Lithium-Ion Batteries Using Acoustic Emission, J. Electrochem. Soc. 157 (2010) A1354-A1360. doi:10.1149/1.3489374.

[22] S. Kalnaus, K. Rhodes, C. Daniel, A study of lithium ion intercalation induced fracture of silicon particles used as anode material in Li-ion battery, J. Power Sources. 196 (2011) 8116-8124. doi:10.1016/j.jpowsour.2011.05.049.

[23] C. Villevieille, M. Boinet, L. Monconduit, Direct evidence of morphological changes in conversion type electrodes in Li-ion battery by acoustic emission, Electrochem. Commun. 12 (2010) 1336-1339. doi:10.1016/j.elecom.2010.07.014.

[24] N. Kircheva, S. Genies, D. Brun-Buisson, P.X. Thivel, Study of Solid Electrolyte Interface Formation and Lithium Intercalation in Li-Ion Batteries by Acoustic Emission, J. Electrochem. Soc. 159 (2012) A18-A25. doi:Doi 10.1149/2.045201jes.

[25] B. Dev, M.E. Walter, G.B. Arkenberg, S.L. Swartz, Mechanical and thermal characterization of a ceramic/glass composite seal for solid oxide fuel cells, J. Power Sources. 245 (2014) 958966. doi:10.1016/j.jpowsour.2013.07.054.

[26] B. Dev, M.E. Walter, Comparative study of the leak characteristics of two ceramic/glass composite seals for solid oxide fuel cells, Fuel Cells. 15 (2015) 115-130.

doi:10.1002/fuce.201400095. 
[27] B. Legros, P.-X. Thivel, Y. Bultel, M. Boinet, R.P. Nogueira, Electrochemical Impedance and Acoustic Emission Survey of Water Desorption in Nafion Membranes, Electrochem. SolidState Lett. 12 (2009) B116-B118. doi:10.1149/1.3131728.

[28] B. Legros, P.X. Thivel, F. Druart, Y. Bultel, R. Nogueira, Diagnosis and Modelling of ProtonExchange-Membrane Fuel Cell via and Acoustic-Emission Measurements, in: Electromotion, Lille, 2009: pp. 1-6. doi:10.1109/ELECTROMOTION.2009.5259133.

[29] B. Legros, P.X. Thivel, Y. Bultel, M. Boinet, R.P. Nogueira, Acoustic emission: Towards a realtime diagnosis technique for Proton exchange membrane fuel cell operation, J. Power Sources. 195 (2010) 8124-8133. doi:10.1016/j.jpowsour.2010.07.045.

[30] A.B. Pandit, J. Varley, R.B. Thorpe, J.F. Davidson, Measurement of bubble size distribution: an acoustic technique, Chem. Eng. Sci. 47 (1992) 1079-1089. doi:10.1016/0009-2509(92)802333.

[31] G.G. Yen, H. Lu, Acoustic emission data assisted process monitoring, ISA Trans. 41 (2002) 273-282. doi:10.1016/S0019-0578(07)60087-1.

[32] W. Jingdai, R. Congjing, Y. Yongrong, Characterization of Flow Regime Transition and Particle Motion Using Acoustic Emission Measurement in a Gas-Solid Fluidized Bed, AIChE J. 56 (2010) 1173-1183. doi:10.1002/aic.

[33] L. Fang, Y. Liang, Q. Lu, X. Li, R. Liu, X. Wang, Flow noise characterization of gas-liquid twophase flow based on acoustic emission, Measurement. 46 (2013) 3887-3897. doi:10.1016/j.measurement.2013.07.032.

[34] S. Al-lababidi, A. Addali, H. Yeung, D. Mba, F. Khan, Gas Void Fraction Measurement in TwoPhase Gas/Liquid Slug Flow Using Acoustic Emission Technology, J. Vib. Acoust. 131 (2009) 17. doi:10.1115/1.4000463.

[35] S. Husin, A. Addali, D. Mba, Feasibility study on the use of the Acoustic Emission technology for monitoring flow patterns in two phase flow, Flow Meas. Instrum. 33 (2013) 251-256. doi:10.1016/j.flowmeasinst.2013.07.011.

[36] T.G. Crowther, A.P. Wade, P.D. Wentzell, R. Gopal, Characterization of acoustic emission from an electrolysis cell, Anal. Chim. Acta. 254 (1991) 223-234. doi:10.1016/0003-2670(91)900309.

[37] I. Dedigama, P. Angeli, N. Van Dijk, J. Millichamp, D. Tsaoulidis, P.R. Shearing, D.J.L. Brett, Current density mapping and optical flow visualisation of a polymer electrolyte membrane water electrolyser, J. Power Sources. 265 (2014) 97-103. doi:10.1016/j.jpowsour.2014.04.120.

[38] S.S. Lafmejani, A.C. Olesen, S.K. Kaer, Analysing Gas-Liquid Flow in PEM Electrolyser MicroChannels, ECS Trans. 75 (2016) 1121-1127.

[39] S.S. Lafmejani, A.C. Olesen, S.A. Shakhshir, S.K. Kaer, Analysing Gas-Liquid Flow in PEM Electrolyser Micro-Channels using a Micro-Porous Ceramic as Gas Permeable wall, ECS Trans. 80 (2017) 1107-1115.

[40] J. Mo, Z. Kang, S.T. Retterer, D.A. Cullen, T.J. Toops, J.B. Green, M.M. Mench, F.-Y. Zhang, Discovery of true electrochemical reactions for ultrahigh catalyst mass activity in water splitting, Sci. Adv. 2 (2016) e1600690-e1600690. doi:10.1126/sciadv.1600690.

[41] J. Mo, Z. Kang, G. Yang, D. Talley, Visualization on Rapid and Micro-Scale Dynamics of Oxygen Bubble Evolution in PEMECs, in: Proc. 12th IEEE Int. Conf. Nano/Micro Eng. Mol. Syst., Los Angeles, 2017: pp. 101-105.

[42] Z. Kang, G. Yang, J. Mo, Y. Li, S. Yu, D.A. Cullen, S.T. Retterer, T.J. Toops, G. Bender, B.S. 
Pivovar, J.B. Green, F.Y. Zhang, Novel thin/tunable gas diffusion electrodes with ultra-low catalyst loading for hydrogen evolution reactions in proton exchange membrane electrolyzer cells, Nano Energy. 47 (2018) 434-441. doi:10.1016/j.nanoen.2018.03.015.

[43] J. Nie, Y. Chen, S. Cohen, B.D. Carter, R.F. Boehm, Numerical and experimental study of threedimensional fluid flow in the bipolar plate of a PEM electrolysis cell, Int. J. Therm. Sci. 48 (2009) 1914-1922. doi:10.1016/j.ijthermalsci.2009.02.017.

[44] H. Ito, T. Maeda, A. Nakano, Y. Hasegawa, N. Yokoi, C.M. Hwang, M. Ishida, A. Kato, T. Yoshida, Effect of flow regime of circulating water on a proton exchange membrane electrolyzer, Int. J. Hydrogen Energy. 35 (2010) 9550-9560. doi:10.1016/j.ijhydene.2010.06.103.

[45] D.J. McClements, Ultrasonic Characterisation of Emulsions and Suspensions, Adv. Colloid Interface Sci. 37 (1991) 33-72.

[46] M. Strasberg, Gas Bubbles as Sources of Sound in Liquids, J. Acoust. Soc. Am. 28 (1956) 2026. doi:10.1121/1.1908212.

[47] R. Hsi, M. Tay, D. Bukur, G. Tatterson, G. Morrison, Sound spectra of gas dispersion in an agitated tank, Chem. Eng. J. 31 (1985) 153-161. doi:10.1016/0300-9467(85)80056-3.

[48] R. Manasseh, R.F. LaFontaine, J. Davy, I. Shepherd, Y.G. Zhu, Passive acoustic bubble sizing in sparged systems, Exp. Fluids. 30 (2001) 672-682. doi:10.1007/s003480000245.

[49] M.S. Plesset, A. Prosperetti, Bubble Dynamics and Cavitation, Ann. Rev. Fluid Mech. 9 (1977) 145-185.

[50] K. Onda, T. Murakami, T. Hikosaka, M. Kobayashi, R. Notu, K. Ito, Performance Analysis of Polymer-Electrolyte Water Electrolysis Cell at a Small-Unit Test Cell and Performance Prediction of Large Stacked Cell, J. Electrochem. Soc. 149 (2002) A1069. doi:10.1149/1.1492287.

[51] K. Mishima, T. Hibiki, Some characteristics of air-water two-phase flow in small diameter vertical tubes, Int. J. Multiph. Flow. 22 (1996) 703-712. doi:10.1016/0301-9322(96)00010-9. 